\title{
Selection of green super rice (GSR) with high yield, good qualities, and adaptation to climate condition in Phu Yen province (Part two)
}

\author{
Tung T. Nguyen ${ }^{1 *}$, Thang D. Nguyen ${ }^{2}$, Long Hoang ${ }^{3}$, Mai T. T. Nguyen ${ }^{4}$, Thoa T. Pham ${ }^{2}$, \\ Ton T. Dam ${ }^{2}$, Kim Hoang ${ }^{5}$, Zheng Q. T ${ }^{3}$, \& Li Zhikang ${ }^{3}$ \\ ${ }^{1}$ Phu Yen Department of Agriculture and Rural Development, Phu Yen, Vietnam \\ ${ }^{2} \mathrm{Phu}$ Yen Center for Plant Breeding and Technology, Phu Yen, Vietnam \\ ${ }^{3}$ Chinese Academy of Agricultural Sciences, Beijing, China \\ ${ }^{4}$ Phu Yen Plantation and Plant Protection Department, Phu Yen, Vietnam \\ ${ }^{5}$ Faculty of Agronomy, Nong Lam University, Nong Lam University, Ho Chi Minh City, Vietnam
}

\begin{abstract}
ARTICLE INFO
Research paper

Received: January 30, 2018

Revised: March 12, 2018

Accepted: March 24, 2018
\end{abstract}

\section{Keywords}

Adaptation to climate change

Green Super Rice

Intensive farming

Phu Yen

Rice selection

\section{* Corresponding author}

Nguyen Trong Tung

Email: trongtungpy@yahoo.com

\begin{abstract}
The research contents included: basic experiment, production experiment, demonstration trial production of two new rice varieties selected and experimental development of rice cultivation techniques for Tuy Hoa plains. This report presents part two: Results of production experiment, demonstration trial production of two new rice varieties selected in Phu Yen province. The study was conducted in 4 seasons (WinterSpring 2015 - 2016, Summer-Autumn 2016, Winter-Spring 2016 - 2017 and Summer-Autumn 2017) at intensive farming soil area in Hoa My village of Phu Hoa district, and Hoa Thang village of Tay Hoa district, Phu Yen province with 4 advanced rice varieties (GSR65, GSR90, GSR38 and Nam Uu 1245) and ML 48 used as control. Experimental method in accordance with National Technical Regulation QCVN 0155: 2011/BNNPTNT Experiment on value of cultivation and use value of rice varieties. Results of the four production experiments in two selected crops and the four demonstration trial production of two new rice varieties selected, two the GSR65, GSR90 rice varieties had high yield, good quality, good agronomic traits, short growing time (A1), low pest infestation, suitabe for export and success construction demonstration model on farmer field in Phu Yen.

The GSR65 and GSR90 varieties gave the average yield of 79.8 and 81.7 quintals/ha, exceeding $11.92 \%$ and $14.58 \%$ respectively compared to control ML48 reaching 71.3 quintals/ha, and the profit was 30.5$36.7 \%$ higher than that of ML48 at 15.50 million VND/ha. The GSR65 and GSR90 rice cultivation techniques have been developed.
\end{abstract}

Cited as: Nguyen, T. T., Nguyen, T. D., Hoang, L., Nguyen, M. T. T., Pham, T. T., Dam, T. T., Hoang, K., Zheng, Q. T., \& Li, Z. (2018). Selection of green super rice (GSR) with high yield, good qualities, and adaptation to climate condition in Phu Yen province (Part two). The Journal of Agriculture and Development 17(4), 44-52. 


\title{
Tuyển chọn giống lúa siêu xanh (GSR) năng suất cao, chất lượng tốt, thích ứng điều kiện khí hậu ở tỉnh Phú Yên (Phần 2)
}

\author{
Nguyễn Trọng Tùng ${ }^{1 *}$, Nguyễn Đức Thắng ${ }^{2}$, Hoàng Long $^{3}$, Nguyễn Thị Trúc Mai $^{4}$, \\ Phạm Thị Thỏa ${ }^{2}$, Đàm Thanh Tồn ${ }^{2}$, Hoàng Kim ${ }^{5}$, Tian-Qing Zheng ${ }^{3}$ \& Zhikang Li $^{3}$ \\ ${ }^{1}$ Sở Nông Nghiệp Phát Triển Nông Thôn Phú Yên, Phú Yên \\ ${ }^{2}$ Trung Tâm Giống và Kỹ Thuật Cây Trồng Phú Yên, Phú Yên \\ ${ }^{3}$ Viện Hàn Lâm Khoa Học Nông nghiệp Trung Quốc, Bắc Kinh \\ ${ }^{4}$ Chi Cục Trồng Trọt và Bảo Vệ Thực Vật Phú Yên, Phú Yên \\ ${ }^{5}$ Khoa Nông Học, Trường Đại Học Nông Lâm TP. Hồ Chí Minh, TP. Hồ Chí Minh
}

\section{THÔNG TIN BÀI BÁO}

Bài báo khoa học

Ngày nhận: 30/01/2018

Ngày chỉnh sửa: $12 / 03 / 2018$

Ngày chấp nhận: 24/03/2018

\section{Từ khóa}

Chọn giống lúa

Lúa siêu xanh

Phú Yên

Thích ứng với biến đổi khí hậu

Vùng thâm canh

\section{*Tác giả liên hệ}

Nguyễn Trọng Tùng

Email: trongtungpy@yahoo.com

\section{TÓM TẮT}

Đề tài "Tuyển chọn giống lúa siêu xanh (Green Super Rice -GSR) năng suất cao, chất lượng tốt, thích ứng với biến đổi khí hậu tại tỉnh Phú Yên" do Trung tâm Giống và Kỹ thuật Cây trồng Phú Yên chủ trì thực hiện. Nội dung nghiên cứu bao gồm: thí nghiệm cơ bản, thí nghiệm sản xuất, sản xuất thử nghiệm các giống lúa mới được lựa chọn và phát triển thí điểm các kỹ thuật canh tác lúa ở đồng bằng Tuy Hòa. Báo cáo này trình bày phần hai: Kết quả thí nghiệm sản xuất, trình diễn thử nghiệm 2 giống lúa mới được chọn ở Phú Yên. Nghiên cứu được thưc hiện trong 4 vụ liên hoàn (Đông Xuân 2015 - 2016, Hè Thu 2016, Đông Xuân 2016-2017 và Hè Thu 2017) ở vùng đất canh tác thâm canh ở thôn Hòa Mỹ, huyện Phú Hòa, và thôn Hòa Thắng huyện Tây Hoà, tỉnh Phú Yên. Với 4 giống lúa triển vọng (GSR65, GSR90, GSR38 và Nam Ưu 1245) với ML 48 được sử dụng làm đối chứng. Phương pháp khảo nghiệm theo Quy chuẩn kỹ thuật quốc gia QCVN 01-55: 2011/BNNPTNT khảo nghiệm giá trị trồng trọt và giá trị sử dụng của giống lúa. Kết quả của bốn khảo nghiệm sản xuất tại hai điểm hai vụ và bốn mô hình trình diễn sản xuất của hai giống lúa mới được lựa chọn tại hai điểm hai vụ kế tiếp.

Hai giống lúa GSR65, GSR90 có năng suất cao, chất lượng tốt, các đặc tính nông học tốt, thời gian sinh trưởng ngắn (A1), sâu bệnh hại thấp, phù hợp xuất khẩu, và xây dựng thành công mô hình trình diễn trên đồng ruộng của nông dân ở tỉnh Phú Yên. Hai giống lúa GSR65, GSR90 đạt năng suất thực thu bình quân tương ứng là 79,8 và 81,7 tạ/ha vượt $11,92 \%$ và $14,58 \%$ so với đối chứng ML48 đạt 71,3 tạ/ha; lãi thuần vượt 30,5 - 36,7\% so với ML48 đạt 15,50 triệu đồng/ha. Quy trình kỹ thuật canh tác lúa GSR65 và GSR90 đã được xây dựng.

\section{1. Đặt Vấn Đề}

Vùng lúa Phú Yên có diện tích lúa cả năm đạt 57.836 ha chiếm khoảng $51 \%$ diện tích gieo trồng cây hàng năm, với năng suất 62,8 tạ/ha, sản lượng 362.210 tấn (Statistics Office, 2017). ML48 là giống lúa chủ lực trên địa bàn tỉnh có năng suất cao, ngắn ngày, chất lượng gạo khá. Đề tài nghiên cứu khoa học và phát triển công nghệ cấp Tỉnh "Tuyển chọn giống lúa siêu xanh (Green Super Rice-GSR) năng suất cao, phẩm chất tốt, thích ứng với biến đổi khí hậu tại tỉnh Phú Yên" nhằm khai thác thành tựu nổi bật mới của bộ giống lúa siêu xanh để bổ sung lúa giống tốt năng suất cao, chất lượng tốt, thích ứng với biến đồi khí hậu cho sản xuất lúa (Zhang, 2007; Hoang \& ctv., 2015; IRRI, 2016). "Kết quả khảo nghiệm cơ bản bộ giống lúa siêu xanh (GSR) tại tỉnh Phú Yên" phần 1 đã so sánh sự sinh trưởng phát triển, năng suất và chất lượng của 12 giống lúa GSR36, GSR38, GSR54, GSR63, GSR65, GSR84, GSR89, GSR90, GSR131, Nam Ưu 1241, Nam Ưu 1245 
và ML 48. Kết quả đã tuyển chọn được 4 giống lúa triển vọng GSR65, GSR90, GSR38, Nam Ưu 1245 có năng suất cao, chất lượng tốt, đặc tính nông học tốt, thời gian sinh trưởng ngắn ngày A1, ít nhiễm các sâu bệnh hại chính để đưa vào khảo nghiệm sản xuất và xây dựng mô hình trình diễn trên ruộng nông dân tại Phú Yên. Mục tiêu nghiên cứu này (phần 2) nhằm tuyển chọn và xác định được 1-2 giống lúa tốt nhất từ khảo nghiệm sản xuất 5 giống lúa triển vọng và xây dựng mô hình trình diễn sản xuất thử cho giống lúa mới tuyển chọn.

\section{Vật Liệu và Phương Pháp Nghiên Cứu}

\subsection{Vật liệu}

4 giống lúa tuyển chọn cho khảo nghiệm sản xuất gồm GSR65, GSR90, GSR38, Nam Ủu 1245 và 01 giống đối chứng ML48 (Bảng 1).

ML48 là giống lúa đối chứng trồng phổ biến tại Phú Yên. Bốn giống lúa GSR 65, GSR90, GSR38, Nam ưu 1245 đã được tuyển chọn qua khảo nghiệm cơ bản trực tiếp tại tỉnh Phú Yên ở hai địa điểm ba vụ.

\section{2. Điều kiện thí nghiệm và nội dung nghiên cứu}

\subsection{1. Điều kiện thí nghiệm}

Khảo nghiệm sản xuất gồm 4 thí nghiệm so sánh sinh trưởng năng suất 5 giống lúa hai vụ tại hai địa điểm ở tỉnh Phú Yên. Thí nghiệm nghiên cứu xác định lượng giống sạ và mức bón đạm cho giống lúa tốt nhất được tuyển chọn gồm 4 thí nghiệm hai yếu tố giống và mức bón đạm được bố trí hai vụ tại hai địa điểm ở tỉnh Phú Yên. Điểm 1 Cánh đồng Đội 1 , xã Hoà Thắng, huyện Phú Hòa; Điểm 2: Cánh đồng Cây Trảy, xã Hoà Mỹ, huyện Tây Hòa. Đặc điểm đất đai tưới tiêu khí hậu thời tiết: cả hai địa điểm đều đất thịt, pha cát có độ phì trung bình, nhiễm phèn nhẹ; điều kiện cơ sở hạ tầng, thủy lợi cơ bản đáp ứng yêu cầu để bố trí thí nghiệm; tưới tiêu nước hoàn toàn chủ động. Khí hậu thời tiết của 4 vụ liên hoàn cho 8 thí nghiệm Đông Xuân 2015-2016, Hè Thu 2016, Đông Xuân 2016-2017, Hè Thu 2017 ở hai điểm tuy có diễn biến khác nhau nhưng nhìn chung đều thuận lợi thí nghiệm, vụ Đông Xuân có điều kiện phù hợp và thuận lợi hơn cho sự sinh trưởng và năng suất lúa so với vụ Hè Thu.

\subsubsection{Nội dung nghiên cứu}

Khảo nghiệm sản xuất 5 giống lúa tại 2 điểm 2 vụ, xác định giống lúa tốt nhất có thời gian sinh trưởng ngắn, năng suất và chất lượng tốt, ít nhiễm sâu bệnh hại chính trên đồng ruộng, thích nghi với điều kiện sản xuất tại Phú Yên. 2) Xây dựng mô hình trình diễn sản xuất thử hai giống lúa mới tuyển chọn; nghiên cứu xác định lượng giống gieo sạ và liều lượng phân đạm phù hợp cho giống lúa mới tốt nhất được tuyển chọn tại 2 điểm 2 vụ; xây dựng quy trình kỹ thuật canh tác lúa cho vùng đồng bằng Tuy Hòa.

\subsection{Phương pháp nghiên cứu}

2.3.1. Khảo nghiệm sản xuất 5 giống lúa tại 2 điểm 2 vụ

Bốn khảo nghiệm sản xuất, quy mô 2 ha, kiểu bố trí khảo nghiệm, quy trình kỹ thuật canh tác, chỉ tiêu theo dõi được thực hiện theo đúng quy chuẩn kỹ thuật quốc gia về Khảo nghiệm giá trị canh tác và giá trị sử dụng của giống lúa (MARD, 2011). 5 giống lúa $\times 1000 \mathrm{~m}^{2} /$ giống $\times 2$ điểm $\times 2$ vụ $=2$ ha. Đánh giá năng suất thực thu, năng suất lý thuyết, các yếu tố cấu thành năng suất, các đặc tính nông sinh học của các giống: Nhận xét chung về sinh trưởng, mức độ nhiễm sâu bệnh và khả năng thích ứng với điều kiện địa phương nơi khảo nghiệm. Thời gian sinh trưởng tính từ gieo đến khí lúa chín 85-90\% số hạt. Năng suất cân khối lượng thực thu trên diện tích khảo nghiệm, quy ra năng suất (tạ/ha), độ ẩm 14\%; ghi nhận mức độ chấp nhận của người sản xuất và ý kiến của cơ quan chuyên môn ở địa phương về sự chấp nhận giống mới. Đánh giá phản ứng của bốn giống lúa GSR 65, GSR 38, GSR 90, Nam Uu 1245 đối với rầy nâu và bệnh đạo ôn trong điều kiện nhà lưới Viện Bảo vệ Thực vật. Số liệu thí nghiệm được cập nhật, tính toán bằng Excel và xử lý số liệu bằng phần mềm Statistix 10.

2.3.2. Xây dựng mô hình trình diễn sản xuất thử hai giống lúa mới tuyển chọn và xây dựng quy trình kỹ thuật canh tác lúa cho vùng đồng bằng Tuy Hò̀a

Nội dung chi tiết bao gồm: 1) Xây dựng mô hình trình diễn đối với giống lúa GSR65, GSR90 với ML48 so sánh năng suất và hiệu quả kinh tế. 2) Nghiên cứu xác định lượng giống gieo sạ và liều lượng phân đạm phù hợp cho giống lúa mới được tuyển chọn tại 2 điểm 2 vụ, gồm bốn thí nghiệm 
Bảng 1. Danh sách 5 giống lúa khảo nghiệm sản xuất và nguồn gốc xuất xứ

\begin{tabular}{cccc}
\hline TT & Tên giống & Tên gốc/tổ hợp lai & Nơi và năm nhận giống \\
\hline 1 & GSR65 & HHZ5-DT11-SAL2-7 & GSR/LP 2013 \\
2 & GSR90 & OM9921x GSR38 & GSR/LP 2013 \\
3 & GSR38 & HHZ5-Y7-Y3 & GSR/LP 2013 \\
4 & Nam ưu 1245 & TQ/OM4900 & SSC 2010 \\
5 & ML48 (Đ/C) & OM576 chọn lọc & Trại giống lúa Ma Lâm, Bình Thuận \\
\hline
\end{tabular}

hai yếu tố được thiết kế theo kiểu ô chính ô phụ (SPD), với 4 lượng giống gieo sạ $\mathrm{G}_{60}, \mathrm{G}_{90}, \mathrm{G}_{120}$, $\mathrm{G}_{140}$ và 4 công thức bón đạm $\mathrm{N}_{60}, \mathrm{~N}_{80}, \mathrm{~N}_{100}, \mathrm{~N}_{120}$ bố trí 3 lần lặp lại. Diện tích ô phụ $20 \mathrm{~m}^{2}$,diện tích ô lớn $80 \mathrm{~m}^{2}$. Tổng diện tích thí nghiệm 4.680 $\mathrm{m}^{2}\left(1.170 \mathrm{~m}^{2} /\right.$ điểm$/ \mathrm{vu} \times 2$ vụ $\times 2$ điểm $)$, khoảng cách giữa các ô phụ $0,3 \mathrm{~cm}$, giữa các lần lặp là $0,5 \mathrm{~cm}$ và hàng rào bảo vệ xung quanh là $1 \mathrm{~m}$ ); 3) Xây dựng quy trình kỹ thuật canh tác lúa cho vùng đồng bằng Tuy Hòa.

\section{Kết Quả và Thảo Luận}

\subsection{Năng suất của 5 giống lúa tại hai điểm hai vụ ở Phú Yên}

Năng suất thực thu (NSTT) là chỉ tiêu quan trọng hàng đầu trong chọn giống lúa. Kết quả khảo nghiệm sản xuất 5 giống lúa qua 2 vụ tại 2 điểm ở Phú Yên được thể hiện ở Bảng 2.

Năng suất thực thu bình quân của 5 giống lúa khảo nghiệm sản xuất (KNSX) dao động từ 72,9 80,8 tạ/ha. Hai giống lúa GSR65 và GSR90 năng suất thực thu cao nhất tương ứng là 80,8 và 80,3 tạ/ ha vượt $10,83 \%$ và $10,85 \%$ so với đối chứng ML48 đạt 72,9 tạ/ha. Đối chiếu với kết quả của 6 thí nghiệm khảo nghiệm cơ bản (KNCB) thì hai giống lúa GSR65 và GSR90 đã thể hiện sự vượt trội rõ rệt so với ML48 về năng suất thực thu.

Năng suất lý thuyết (NSLT) bình quân của của 5 giống lúa khảo nghiệm sản xuất dao động từ $82,4-110,1$ tạ/ha. Hai giống lúa GSR90 và GSR65 có năng suất lý thuyết cao nhất vượt đối chứng ML48 lần lượt là 33,61\% và 21,11\% (Bảng $3)$.

So sánh năng suất lý thuyết bình quân của 4 khảo nghiệm sản xuất với năng suất lý thuyết bình quân của 6 khảo nghiệm cơ bản thì hai giống lúa GSR90, GSR65 đều thể hiện sự vượt trội hơn hẵn về năng suất lý thuyết so với ML48. Đồng thời, hai giống lúa này cũng thể hiện sự nổi bật ở vùng mặn (Dang \& ctv., 2015).

\section{2. Đặc điểm nông sinh học của 5 giống lúa tại hai điểm hai vụ ở Phú Yên}

Phân tích số liệu 5 giống lúa khảo nghiệm sản xuất về số bông $/ \mathrm{m}^{2}$, số hạt chắc trên bông và khối lượng 1.000 hạt $(\mathrm{g})$. Kết quả ghi nhận tại Bảng 4, Bảng 5, Bảng 6 cho thấy hai giống lúa mới GSR65 và GSR90 đều thể hiện số liệu nổi trội so với đối chứng ML48.

Đánh giá kết quả số bông $/ \mathrm{m}^{2}\left(\mathrm{SB} / \mathrm{m}^{2}\right)$ của 5 giống lúa KNSX qua hai vụ tại hai điểm ở Phú Yên, Bảng 4 đã chỉ ra rằng: Hai giống lúa GSR65 và GSR90 có nhiều bông hơn so đối chứng ML48. Ở phương thức gieo sạ với lượng giống gieo 120 $\mathrm{kg}$ /ha và mức phân bón $100 \mathrm{~N}-90 \mathrm{P}_{2} \mathrm{O}_{5}-80 \mathrm{~K}_{2} \mathrm{O}$ + 10 tấn phân chuồng hoai mục cho 1ha thì số bông $/ \mathrm{m}^{2}$ của 5 giống lúa KNSX tại hai vụ ở hai điểm đều cao hơn so phương thức cấy của sáu khảo nghiệm cơ bản.

Bảng 5 cho thấy: Hai giống lúa GSR65 và GSR90 có số hạt chắc trên bông bình quân nhiều hơn so đối chứng ML48. Tuy vậy, số hạt chắc trên bông (SHCTB) của 5 giống lúa KNSX tại hai vụ ở hai điểm của phương thức gieo sạ thì thấp hơn so phương thức cấy của sáu khảo nghiệm cơ bản khi lượng hạt giống sạ $120 \mathrm{~kg} /$ ha. Sự nghiên cứu lượng giống gieo sạ là cần thiết.

Bảng 6 đã chỉ ra khối lượng 1.000 hạt (g) bình quân của bốn giống lúa mới khảo nghiệm sản xuất đều cao hơn hoặc bằng so với đối chứng. Hai giống lúa mới GSR65 và GSR90 có khối lượng 1.000 hạt (g) bình quân tương ứng là $25 \mathrm{~g}$ và $28 \mathrm{~g}$.

Kết quả khảo nghiệm (Bảng 7) cho thấy 5 giống lúa khảo nghiệm đều ngắn ngày $\left(\mathrm{A}_{1}\right)$ trổ tập trung, thời gian sinh trưởng từ gieo sạ đến thu hoạch dao động từ 95 đến 105 ngày.

Các giống lúa GSR65, GSR90, GSR38, Nam Ưu 1265 đều có đặc điểm nông sinh học tốt (Bảng 8), dạng hình lúa siêu xanh, bộ lá xanh lâu bền (điểm 1), thấp cây (điểm 1), cứng cây không đổ ngã (điểm 1), độ thoát cổ bông cao (điểm 1), 
Bảng 2. Năng suất thực thu của 5 giống khảo nghiệm sản xuất qua hai vụ tại hai điểm

\begin{tabular}{|c|c|c|c|c|c|c|c|c|}
\hline \multirow{5}{*}{ Giống lúa } & \multicolumn{6}{|c|}{ Năng suất thực thu (tạ/ha) KNSX qua 2 vụ 2 điểm } & \multicolumn{2}{|c|}{ So $\mathrm{KNCB}(*)$} \\
\hline & Tây & Tây & Phú & Phú & NSTT & & & NSTT \\
\hline & Hòa & Hòa & Hòa & Hòa & & SO với & & So với \\
\hline & ĐX & HT & ĐX & HT & binh quan & ĐC & binh quan & ĐC \\
\hline & $15-16$ & 2016 & $15-16$ & 2016 & & $(\%)$ & & $(\%)$ \\
\hline GSR65 & 82,8 & 81,5 & 80,0 & 78,9 & 80,8 & 110,83 & 87,08 & 130,12 \\
\hline GSR90 & 80,5 & 79,6 & 82,1 & 78,8 & 80,3 & 110,15 & 83,66 & 125,01 \\
\hline Nam Ủu 1245 & 77,2 & 75,2 & 78,0 & 76,7 & 76,8 & 105,34 & 80,83 & 120,78 \\
\hline GSR38 & 76,1 & 75,7 & 75,1 & 76,3 & 75,8 & 103,97 & 80,49 & 120,27 \\
\hline ML48 (Đ/C) & 74,6 & 71,3 & 73,9 & 71,8 & 72,9 & 100,00 & 66,92 & 100,00 \\
\hline
\end{tabular}

(*) KNCB 6 thí nghiệm.

Bảng 3. Năng suất lý thuyết của 5 giống lúa khảo nghiệm sản xuất qua hai vụ tại hai điểm

\begin{tabular}{|c|c|c|c|c|c|c|c|c|}
\hline \multirow{5}{*}{ Giống lúa } & \multicolumn{4}{|c|}{ Năng suất lý thuyết (tạ/ ha) } & \multicolumn{2}{|c|}{ KNSX qua 2 vụ 2 diểm } & \multicolumn{2}{|c|}{ So KNCB $(*)$} \\
\hline & Tây & Tây & Phú & Phú & NSLT & NSLT & & NSLT \\
\hline & Hòa & Hòa & Hòa & Hòa & NSLI & so với & & so với \\
\hline & ĐX & $\mathrm{HT}$ & ĐX & $\mathrm{HT}$ & binh quân & ĐC & binh quân & ĐC \\
\hline & $15-16$ & 2016 & $15-16$ & 2016 & & $(\%)$ & & $(\%)$ \\
\hline GSR65 & 100,4 & 99,0 & 102,3 & 97,6 & 99,8 & 121,11 & 99,50 & 133,35 \\
\hline GSR90 & 112,9 & 109,0 & 107,4 & 111,0 & 110,1 & 133,61 & 102,93 & 137,93 \\
\hline Nam U’u 1245 & 88,2 & 91,0 & 91,7 & 89,7 & 90,2 & 109,46 & 96,48 & 129,29 \\
\hline GSR38 & 97,6 & 100,0 & 99,8 & 96,8 & 98,5 & 119,59 & 94,99 & 127,30 \\
\hline $\operatorname{ML} 48(Đ / C)$ & 82,8 & 81,8 & 81,9 & 83,2 & 82,4 & 100,00 & 74,62 & 100,00 \\
\hline $\mathrm{CV} \%$ & 12,43 & 14,67 & 11,85 & 12,49 & & & & \\
\hline LSD0.05 & 5,97 & 7,23 & 8,15 & 6,89 & & & & \\
\hline
\end{tabular}

(*) KNCB 6 thí nghiệm.

Bảng 4. Số bông $/ \mathrm{m}^{2}$ của 5 giống lúa KNSX hai vụ tại hai điểm ở Phú Yên

\begin{tabular}{|c|c|c|c|c|c|c|c|}
\hline \multirow{2}{*}{ Tên giống } & \multicolumn{6}{|c|}{ Số bông /m2 (bông) KNSX hai vụ tại hai địa điểm } & \multirow{2}{*}{$\begin{array}{c}\text { KNCB } \\
\text { bình quân } \\
\text { SB/m2 }\end{array}$} \\
\hline & $\begin{array}{c}\text { Tây Hòa } \\
\text { ĐX } \\
15-16\end{array}$ & $\begin{array}{c}\text { Tây Hòa } \\
\text { HT } \\
2016\end{array}$ & $\begin{array}{c}\text { Phú Hòa } \\
\text { ĐX } \\
15-16\end{array}$ & $\begin{array}{c}\text { Phú Hòa } \\
\text { HT } \\
2016\end{array}$ & $\begin{array}{c}\text { Bình quân } \\
\text { SB/m2 }\end{array}$ & $\begin{array}{c}\% \\
\text { so } \\
\text { đối chứng }\end{array}$ & \\
\hline GSR65 & 355 & 350 & 359 & 355 & 354,75 & 116,79 & 336,76 \\
\hline GSR90 & 360 & 347 & 355 & 344 & 351,50 & 115,72 & 309,57 \\
\hline Nam U’u 1245 & 340 & 328 & 337 & 326 & 332,75 & 109,54 & 300,89 \\
\hline GSR38 & 348 & 340 & 342 & 325 & 338,75 & 111.52 & 300,06 \\
\hline $\operatorname{ML} 48(\mathrm{D} / \mathrm{C})$ & 312 & 285 & 318 & 300 & 303,75 & 100,00 & 278,89 \\
\hline
\end{tabular}

Bảng 5. Số hạt chắc trên bông của 5 giống lúa KNSX hai vụ tại hai điểm ở Phú Yên

\begin{tabular}{|c|c|c|c|c|c|c|c|}
\hline \multirow{2}{*}{ Tên giống } & \multicolumn{6}{|c|}{ Số hạt chắc trên bông (hạt) KNSX hai vụ tại hai địa điểm } & \multirow{2}{*}{$\begin{array}{c}\text { KNCB } \\
\text { bình quân } \\
\text { SHCTB }\end{array}$} \\
\hline & $\begin{array}{c}\text { Tây Hòa } \\
\text { ĐX } \\
15-16\end{array}$ & $\begin{array}{c}\text { Tây Hòa } \\
\text { HT } \\
2016\end{array}$ & $\begin{array}{c}\text { Phú Hòa } \\
\text { ĐX } \\
15-16\end{array}$ & $\begin{array}{c}\text { Phú Hòa } \\
\text { HT } \\
2016\end{array}$ & $\begin{array}{c}\text { Bình quân } \\
\text { SHCTB }\end{array}$ & $\begin{array}{c}\% \\
\text { so } \\
\text { đối chứng }\end{array}$ & \\
\hline GSR65 & 110 & 107 & 114 & 110 & 110,25 & 112,78 & 124,33 \\
\hline GSR90 & 112 & 109 & 108 & 112 & 110,25 & 112,78 & 117,11 \\
\hline Nam Ưu 1245 & 105 & 109 & 107 & 105 & 106,50 & 108,95 & 127,66 \\
\hline GSR38 & 101 & 103 & 105 & 101 & 102,50 & 104,85 & 120,41 \\
\hline ML48 (Đ/C) & 98 & 96 & 98 & 99 & 97,75 & 100,00 & 111,94 \\
\hline
\end{tabular}


Bảng 6. Khối lượng 1.000 hạt $(\mathrm{g})$ của 5 giống lúa KNSX hai vụ tại hai điểm ở Phú Yên

\begin{tabular}{|c|c|c|c|c|c|c|c|}
\hline \multirow{4}{*}{ Tên giống } & \multicolumn{6}{|c|}{ Khối lượng 1.000 hạt $(\mathrm{g})$ KNSX hai vụ tại hai địa điểm } & \multirow{4}{*}{$\begin{array}{c}\text { KNCB } \\
\mathrm{P}_{1.000} \text { hạt } \\
\text { bình quân } \\
\text { (g) }\end{array}$} \\
\hline & Tây Hòa & Tây Hòa & Phú Hòa & Phú Hòa & $\mathrm{P}_{1.000}$ hạt & $\%$ & \\
\hline & ĐX & HT & ĐX & HT & bình quân & so & \\
\hline & $15-16$ & 2016 & $15-16$ & 2016 & $(\mathrm{~g})$ & đối chứng & \\
\hline GSR65 & 25 & 25 & 25 & 25 & 25 & 104,16 & 24,0 \\
\hline GSR90 & 28 & 28 & 28 & 28 & 28 & 116,66 & 28,4 \\
\hline Nam Ưu 1245 & 24 & 24 & 24 & 24 & 24 & 100,00 & 25,2 \\
\hline GSR38 & 27 & 27 & 27 & 27 & 27 & 112,50 & 26,4 \\
\hline ML48 (Đ/C) & 24 & 24 & 24 & 24 & 24 & 100,00 & 23,8 \\
\hline
\end{tabular}

Bảng 7. Thời gian sinh trưởng (ngày) của 5 giống lúa KNSX hai vụ tại hai điểm ở Phú Yên

\begin{tabular}{|c|c|c|c|c|c|c|c|}
\hline \multirow{2}{*}{ Tên giống } & \multicolumn{6}{|c|}{ Thời gian sinh trưởng (ngày sau sạ) KNSX hai vụ tại hai địa điểm } & \multirow{2}{*}{$\begin{array}{c}\text { TGST } \\
\text { bình quân } \\
\left(\mathrm{NSC}^{* *}\right)\end{array}$} \\
\hline & $\begin{array}{c}\text { Tây Hòa } \\
\text { ĐX } \\
15-16\end{array}$ & $\begin{array}{c}\text { Tây Hòa } \\
\text { HT } \\
2016\end{array}$ & $\begin{array}{c}\text { Phú Hòa } \\
\text { ĐX } \\
15-16\end{array}$ & $\begin{array}{c}\text { Phú Hòa } \\
\text { HT } \\
2016\end{array}$ & $\begin{array}{c}\text { TGST } \\
\text { bình quân } \\
\text { (NSS*) }\end{array}$ & $\begin{array}{l}\text { Phân } \\
\text { loại } \\
\text { giống }\end{array}$ & \\
\hline GSR65 & 98 & 95 & 97 & 95 & 96,24 & $\mathrm{~A}_{1}$ & 105,3 \\
\hline GSR90 & 104 & 100 & 105 & 102 & 102,75 & $\mathrm{~A}_{1}$ & 104,5 \\
\hline Nam U’u 1245 & 99 & 96 & 97 & 96 & 97,00 & $\mathrm{~A}_{1}$ & 106,8 \\
\hline GSR38 & 105 & 101 & 105 & 103 & 103,50 & $\mathrm{~A}_{1}$ & 107,2 \\
\hline ML48 (Đ/C) & 97 & 94 & 95 & 104 & 95,25 & $\mathrm{~A}_{1}$ & 99,8 \\
\hline
\end{tabular}

*NSS ngày sau sạ, **NSC ngày sau cấy.

dạng hạt gạo thon dài, được người trồng lúa và thị trường ưa chộng.

\subsection{Tình hình sâu bệnh hại của 5 giống lúa tại hai điểm hai vụ ở Phú Yên}

Kết quả khảo nghiệm (Bảng 9) cho thấy bệnh khô vằn (Rhizoctonia solani) hầu như không ghi nhận đối với các giống GSR90, GSR65, GSR38 hoặc rất nhẹ ở giống Nam Ưu 1245 nhưng giống đối chứng ML48 bị nhiễm trung bình (điểm 35) ở vụ Hè Thu tại 2 điểm. Các giống GSR38, GSR65 không có vết bệnh đạo ôn lá (Pyricularia oryzae) và đạo ôn cổ bông (Pyricularia oriseae) ở cả 2 vụ Đông Xuân và Hè Thu; Các giống khác với mức độ thấp từ điểm 1 đến điểm 3 . Giống GSR65 và GSR38 qua hai vụ khảo nghiệm thể hiện tính chống chịu tốt nhất, sau đó là GSR90, Nam Ưu 1245, thấp nhất là đối chứng ML48.

\subsection{Phản ứng của các giống lúa với rầy nâu và đạo ôn trong điều kiện phòng thí nghiệm}

Kết quả đánh giá phản ứng của 4 giống lúa đối với rầy nâu và bệnh đạo ôn hại lúa Bảng 10 cho thấy: 3 giống lúa GSR 90, GSR65 và GSR38 kháng vừa rầy nâu với cấp điểm tương ứng là 4,5 ; 4,5 và 4,0 . Giống lúa Nam Ủu 1245 có phản ứng nhiễm vừa rầy nâu (cấp điểm tương ứng là 5,5$)$. 3 giống lúa GSR38, GSR65 và Nam Ưu 1245 có phản ứng nhiễm vừa với bệnh đạo ôn hại lúa (cấp điểm tương ứng 6,$0 ; 6,5$ và 6,5 ), giống lúa GSR90 có phản ứng nhiễm đạo ôn (cấp điểm 7,0 ).

\subsection{Kết quả xây dựng mô hình trình diễn giống lúa GSR65, GSR90 tại Phú Yên}

Năng suất thực thu và năng suất lý thuyết của mô hình trình diễn ba giống lúa GSR65, GSR90 và ML48 tại hai điểm Tây Hòa và Phú Hòa trong hai vụ thể hiện ở Bảng 11. Kết quả hai giống lúa GSR65 và GSR90 đạt năng suất thực thu tương ứng là 79,8 và 81,7 tạ/ ha vượt $11,92 \%$ và $14,58 \%$ so với đối chứng ML48 đạt 71,3 tạ/ha. Năng suất lý thuyết bình quân của hai giống lúa GSR65 và GSR90 tại hai điểm hai vụ vượt $13,08 \%$ và $21,18 \%$ so với ML48.

Hiệu quả kinh tế của mô hình trình diễn giống lúa GSR65 và GSR90 trong vụ ĐX 2016-2017 và HT 2017 được thể hiện ở Bảng 12. Giống lúa ML48 tổng thu đạt 36,40 triệu đồng/ha vụ Đông Xuân 2016-2017 và 34,97 triệu đồng/ha vụ Hè Thu 2017, với lãi thuần tương ứng đạt 16,22 và 14,79 triệu đồng/ha. Giống lúa GSR90 đạt tổng thu 41,40 triệu đồng/ha vụ Đông Xuân 20162017 và 40,25 triệu đồng/ha vụ Hè Thu 2017. 
Bảng 8. Một số đặc điểm nông sinh học của các giống lúa khảo nghiệm ${ }^{1}$

\begin{tabular}{cccccccc}
\hline Giống lúa & $\begin{array}{c}\text { Độ bền } \\
\text { lá siêu xanh }\end{array}$ & $\begin{array}{c}\text { Sắc } \\
\text { tố } \\
\text { antoxian }\end{array}$ & $\begin{array}{c}\text { Tập tính } \\
\text { sinh trưởng }\end{array}$ & $\begin{array}{c}\text { Chiều } \\
\text { cao } \\
\text { cây }\end{array}$ & $\begin{array}{c}\text { Độ } \\
\text { cứng } \\
\text { cây }\end{array}$ & $\begin{array}{c}\text { Độ thoát } \\
\text { cổ bông }\end{array}$ & $\begin{array}{c}\text { Dạng } \\
\text { hạt gạo }\end{array}$ \\
\hline GSR65 & 1 & Không có & Nửa đứng & 1 & 1 & 1 & Thon dài \\
GSR90 & 1 & Không có & Nửa đứng & 1 & 1 & 1 & Thon dài \\
Nam Ưu 1245 & 1 & Không có & Nửa đứng & 1 & 1 & 1 & Thon dài \\
GSR38 & 1 & Không có & Nửa đứng & 1 & 1 & 1 & Thon dài \\
ML48 (Đ/C) & 5 & Không có & Nửa đứng & 1 & 5 & 1 & Thon dài \\
\hline
\end{tabular}

${ }^{1}$ Chỉ tiêu theo dõi và đánh giá được thực hiện theo đúng Quy chuẩn kỹ thuật quốc gia về Khảo nghiệm giá trị canh tác và giá trị sử dụng của giống lúa (MARD, 2011).

Bảng 9. Phản ứng của 5 giống lúa khảo nghiệm với sâu bệnh hại chính tại hai điểm ở Phú Yên

\begin{tabular}{|c|c|c|c|c|c|c|c|c|c|c|}
\hline \multirow{3}{*}{$\begin{array}{l}\text { Địa điểm } \\
\text { và } \\
\text { Giống lúa }\end{array}$} & \multicolumn{2}{|c|}{ Sâu cuốn lá } & \multicolumn{2}{|c|}{ Rầy nâu } & \multicolumn{2}{|c|}{ Khô vằn } & \multicolumn{2}{|c|}{ Đạo ôn lá } & \multicolumn{2}{|c|}{ Đạo ôn cổ bông } \\
\hline & ĐX & HT & ĐX & $\mathrm{HT}$ & ĐX & HT & $\mathrm{DX}$ & $\mathrm{HT}$ & ĐX & HT \\
\hline & $15-16$ & 2016 & $15-16$ & 2016 & $15-16$ & 2016 & $15-16$ & 2016 & $15-16$ & 2016 \\
\hline \multicolumn{11}{|c|}{ Tây Hòa } \\
\hline GSR65 & 0 & 0 & 0 & 0 & 0 & 0 & 0 & 0 & 0 & 0 \\
\hline GSR90 & 1 & 1 & 0 & 1 & 0 & 0 & 3 & 0 & 0 & 0 \\
\hline Nam Ưu 1245 & 1 & 1 & 1 & 1 & 0 & 0 & 3 & 0 & 1 & 0 \\
\hline GSR38 & 0 & 1 & 1 & 1 & 0 & 0 & 0 & 0 & 0 & 0 \\
\hline ML48 (Đ/C) & 1 & 1 & 3 & 3 & 0 & 3 & 3 & 0 & 1 & 0 \\
\hline \multicolumn{11}{|c|}{ Phú Hòa } \\
\hline GSR65 & 1 & 0 & 0 & 0 & 0 & 0 & 0 & 0 & 0 & 0 \\
\hline GSR90 & 1 & 1 & 0 & 0 & 0 & 0 & 3 & 0 & 0 & 0 \\
\hline Nam Ưu 1245 & 1 & 1 & 1 & 1 & 0 & 1 & 1 & 0 & 1 & 0 \\
\hline GSR38 & 1 & 1 & 0 & 1 & 0 & 5 & 0 & 0 & 0 & 0 \\
\hline ML48 (Đ/C) & 1 & 1 & 3 & 3 & 0 & 5 & 3 & 0 & 1 & 0 \\
\hline
\end{tabular}

Bảng 10. Phản ứng của bốn giống lúa đối với rầy nâu và bệnh đạo ôn

\begin{tabular}{|c|c|c|c|c|c|}
\hline \multirow{2}{*}{ Tên giống } & \multicolumn{2}{|c|}{ Rầy nâu } & \multirow{2}{*}{ Tên giống } & \multicolumn{2}{|c|}{ Bệnh đạo ôn } \\
\hline & Cấp hại & $\begin{array}{c}\text { Mức } \\
\text { đánh giá }\end{array}$ & & Cấp hại & $\begin{array}{c}\text { Mức } \\
\text { đánh giá }\end{array}$ \\
\hline GSR65 & 4,5 & Kháng vừa & GSR65 & 6,5 & Nhiễm vừa \\
\hline GSR90 & 4,5 & Kháng vừa & GSR90 & 7,0 & Nhiễm \\
\hline GSR38 & 4,0 & Kháng vừa & GSR38 & 6,0 & Nhiễm vừa \\
\hline Nam U’u 1245 & 5,5 & Nhiễm vừa & Nam Ưu 1245 & 6,5 & Nhiễm vừa \\
\hline TN1 (chuẩn nhiễm) & 9,0 & Nhiễm nặng & B40 (chuẩn nhiễm) & 9,0 & Nhiễm nặng \\
\hline Ptb33 (chuẩn kháng) & 1,5 & Kháng cao & Tẻ tép (chuẩn kháng) & 1,0 & Kháng cao \\
\hline
\end{tabular}

Lãi thuần tương ứng đạt 21,22 và 20,07 triệu đồng/ ha. Giống lúa GSR65 đạt tổng thu 40,20 triệu đồng/ha vụ Đông Xuân 2016-2017 và 39,60 triệu đồng vụ Hè Thu 2017. Lãi thuần tương ứng đạt 20,02 và 19,72 triệu đồng/ha. Lãi thuần bình quân của hai giống lúa mới GSR65 và GSR90 cao hơn ML48 đối chứng 30,5-36,7\%. Giống lúa GSR65 gieo sạ ở mật độ $90 \mathrm{~kg} / \mathrm{ha}$ được bón phân đạm với liều lượng $100 \mathrm{kgN} / \mathrm{ha}$ trên nền phân bón thâm canh, vụ Đông Xuân đã đạt năng suất thực thu 75,6 tạ/ha, vụ Hè Thu đạt 73,9 tạ/ha, lãi thuần tương ứng đạt 21,22 và 20,07 triệu đồng/ha và tỷ suất lợi nhuận bình quân đạt 0,98 . Giống lúa GSR90 gieo sạ ở mật độ 90 /ha được bón phân đạm với liều lượng $100 \mathrm{~kg} \mathrm{~N} / \mathrm{ha}$ trên nền phân bón thâm canh, đạt năng suất thực thu 81,7 tạ/ha, vụ Hè Thu đạt 80,8 tạ/ha, lãi thuần tương ứng 20,02 và 19,72 triệu đồng/ ha và tỷ suất lợi nhuận bình quân đạt 1,02. Từ mô hình trình diễn và kết quả nghiên cứu lượng giống gieo sạ và mức 
Bảng 11. Năng suất thực thu và năng suất lý thuyết của 3 giống lúa trình diễn tại hai điểm hai vụ

\begin{tabular}{|c|c|c|c|c|c|c|c|c|}
\hline \multirow{4}{*}{ Giống lúa } & \multicolumn{6}{|c|}{ Năng suất thực thu (tạ/ ha) KNSX qua 2 vụ 2 điểm } & \multicolumn{2}{|c|}{ So $\operatorname{NSLT}(*)$} \\
\hline & Tây Hò & & Phú Hò & Phú Hò & NSLT & NSTT & NSLT & NSTT \\
\hline & ĐX & $\begin{array}{l}\text { Iay } 110 \mathrm{a} \\
\mathrm{HT}\end{array}$ & ĐX & $\begin{array}{l}\text { HT } \\
\text { HTOd }\end{array}$ & bình & so với & bình & so với \\
\hline & $16-17$ & 2017 & $16-17$ & 2017 & quân & ĐC & quân & $\mathrm{ĐC}$ \\
\hline & & & & & $(0,7110)$ & (110) & $(0,110)$ & $\frac{170)}{11200}$ \\
\hline & & & & & & & 91,1 & \\
\hline $\begin{array}{l}\text { GSR90 } \\
\text { ML48 (Đ/C) }\end{array}$ & 71.5 & 69.4 & 741 & 80,1 & 713 & 100.00 & $\begin{array}{l}104,7 \\
86.4\end{array}$ & $\begin{array}{l}121,18 \\
10000\end{array}$ \\
\hline ML48 (Đ/C) & 71,5 & 69,4 & 74,1 & 70,5 & 11,3 & & 86,4 & 100,00 \\
\hline
\end{tabular}

$\left(^{*}\right)$ So NSLT: Năng suất lý thuyết số liệu bình quân tại hai điểm hai vụ.

Bảng 12. Hiệu quả kinh tế của mô hình trình diễn giống lúa GSR65 và GSR90 trong vụ ĐX 2016-2017 và HT 2017

\begin{tabular}{|c|c|c|c|c|c|c|c|}
\hline \multirow{2}{*}{ Giống lúa } & \multirow{2}{*}{$\begin{array}{l}\text { Tổng chi } \\
\text { (triệu d/ha) }\end{array}$} & \multicolumn{3}{|c|}{ Tồng thu (triệu đ/ha) } & \multicolumn{3}{|c|}{ Lãi thuần (triệu đ/ha) } \\
\hline & & ĐX16-17 & HT2017 & TB & ĐX16-17 & HT2017 & TB \\
\hline GSR65 & 20,18 & 40,20 & 39,60 & $\overline{39,90}$ & 20,02 & 19,42 & $\overline{19,72}$ \\
\hline GSR90 & 20,18 & 41,40 & 40,25 & 40,82 & 21,22 & 20,07 & 20,64 \\
\hline $\operatorname{ML} 48(\mathrm{D} / \mathrm{C})$ & 20,18 & 36,40 & 34,97 & 35,68 & 16,22 & 14,79 & 15,50 \\
\hline
\end{tabular}

Bảng 13. Chất lượng gạo, phẩm chất cơm của 5 giống lúa khảo nghiệm

\begin{tabular}{ccccccccc}
\hline Tên giống & $\begin{array}{c}\text { Tỷ lệ } \\
\text { gạo lật } \\
(\%)\end{array}$ & $\begin{array}{c}\text { Tỷ lẹ̣ } \\
\text { gạo xát } \\
(\%)\end{array}$ & $\begin{array}{c}\text { Tỷ lệ́ } \\
\text { gạo trắng } \\
(\%)\end{array}$ & $\begin{array}{c}\text { Protein } \\
\text { gạo } \\
(*) \\
(\%)\end{array}$ & $\begin{array}{c}\text { Amylose } \\
(*) \\
(\%)\end{array}$ & $\begin{array}{c}\text { Nhiệt độ } \\
\text { hồ hóa } \\
(\text { mức) }\end{array}$ & $\begin{array}{c}\text { Mùi } \\
\text { thơm } \\
(\mathrm{mức})\end{array}$ & $\begin{array}{c}\text { Độ } \\
\text { ngon } \\
(\text { mức) }\end{array}$ \\
\hline GSR65 & 81,2 & 88,4 & 86,2 & 7,77 & 22,52 & $2-1$ & 2 & 2 \\
\hline GSR90 & 79,4 & 87,5 & 73,5 & 7,89 & 24,49 & 1 & 2 & 2 \\
Nam Uu 1245 & 76,5 & 87,7 & 93,7 & 7,55 & 15,67 & 2 & 2 & 2 \\
GSR38 & 77,2 & 86,6 & 83,8 & 7,80 & 25,72 & $2-1$ & 2 & 2 \\
ML48 (Đ/C) & 77,6 & 87,2 & 92,9 & 7,84 & 18,09 & 2 & 2 & 2 \\
\hline
\end{tabular}

(*) Số liệu phân tích do Phòng thí nghiệm của Trung tâm khảo kiểm nghiệm Giống và Sản phẩm cây trồng miền Trung. Mùi thơm 0 không thơm, 1 hơi thơm, 2 thợ; Độ ngon 1 ít ngon, 2 cơm ngon, 3 cơm rất ngon.

bón phân đạm phù hợp cho hai giống lúa siêu xanh GSR65 và GSR90, quy trình kỹ thuật canh tác lúa cho vùng đồng bằng Tuy Hòa đã được xây dựng.

\section{6. Đánh giá chất lượng gạo, phẩm chất cơm của 5 giống lúa khảo nghiệm}

Hai giống lúa GSR65 và GSR90 trong kết quả Bảng 13 đạt chất lượng gạo loại 1 với tỷ lệ gạo lật, tỷ lệ gạo xát và tỷ lệ gạo nguyên cao, gạo trắng thon dài phù hợp thị hiếu tiêu dùng, đạt mức protein cao trên $7 \%$, amylose trung bình, gạo có mùi thơm và cơm ngon.

\section{Kết Luận và Đề Nghị}

\subsection{Kết luận}

Kết quả khảo nghiệm sản xuất và tuyển chọn giống lúa siêu xanh GSR đã xác định được hai giống lúa GSR65, GSR90 năng suất cao, chất lượng gạo tốt, thích ứng điều kiện biến đổi khí hậu và phù hợp gieo trồng tại tỉnh Phú Yên. . Hai giống lúa GSR65, GSR90 trong 4 khảo nghiệm sản xuất có năng suất thực thu tương ứng 80,8 tạ/ha và 80,3 tạ/ha, vượt trên $10 \%$ so với đối chứng ML48 đạt 72,9 tạ/ha; năng suất lý thuyết vượt 21-33\% so với đối chứng ML48; chất lượng gạo loại 1, hạt gạo dạng thon dài, ngon cơm, thơm nhẹ, đủ tiêu chuẩn xuất khẩu; đặc điểm nông sinh học tốt, dạng hình lúa siêu xanh, bộ lá 
xanh lâu bền, thấp cây, cứng cây, không đổ ngã, nhiều bông, bông to chùm, tỷ lệ nhánh hữu hiệu cao, số hạt chắc trên bông cao, khối lượng 1000 hạt tương ứng là 25 và $28 \mathrm{~g}$; thời gian sinh trưởng ngắn ngày $\mathrm{A}_{1}$; ít nhiễm sâu bệnh hại chính, phù hợp gieo trồng tại tỉnh Phú Yên.

Kết quả xây dựng mô hình trình diễn trên ruộng nông dân tại Phú Yên cho thấy hai giống lúa GSR65, GSR90 đạt năng suất thực thu tương ứng là 79,8 và 81,7 tạ/ha vượt $11,92 \%$ và $14,58 \%$ so với đối chứng ML48 đạt 71,3 tạ/ha; năng suất lý thuyết vượt $13,08 \%$ và $21,18 \%$ so với ML48; lãi thuần vượt 30,5-36,7\% so với đối chứng ML48 đạt 15,50\%. Quy trình kỹ thuật canh tác lúa GSR65 và GSR90 đã được xây dựng.

\section{2. Đề nghị}

Sở $\mathrm{NN}$ và $\mathrm{PTNT}$, các địa phương và nông dân sử dụng hai giống lúa GSR90 và GSR65 trong sản xuất đại trà. Tăng cường công tác tuyên truyền về sử dụng hai giống lúa này trong sản xuất, tập huấn cho người nông dân kỹ thuật thâm canh lúa đạt hiệu quả kinh tế cao, nhằm nâng cao giá trị gia tăng trong sản xuất lúa gạo. Sử dụng nguồn gen tốt của bộ giống lúa siêu xanh GSR, đặc biệt là các giống lúa GSR 90, GSR 65 và GSR 38 để lai tạo, tuyển chọn được những giống tốt phù hợp điều kiện Việt Nam.

\section{Tài Liệu Tham Khảo (References)}

Dang, M. V., Tran, L. T., Hoang, L., \& Hoang, K. (2015). Selection of salinity-tolerant rice varieties for adaptation to climate change in Phu Yen. Journal of Agriculture and Rural Development 2, 52-59.

Hoang, L., Li, Z. K., Zheng, T. Q., Hoang, K., Pham, N.T., Tran, L. T., Nguyen, T. T., Nguyen, P. T., \& Le, H. H. (2015). Result of Green Super Rice (GSR) Breeding adaptation to climate change in Vietnam. Conference of Young Scientists hosted by IAS. Ho Chi Minh City, Vietnam: Institute of Agricultural Sciences for Southern Vietnam (IAS).

IRRI (International Rice Research Institute). (2016). Breeding for better rice varieties GSR project updates in Asia and East and Southern Africa. Los Baños, Philippines: Offices in Asia \& Africa. Retrieved August 1, 2016, from http://books.irri.org/GSR-flyer.pdf.

MARD (Ministry of Agriculture and Rural Development). (2011). National technical regulations on cultivation and use values of rice varieties. Ha Noi, Vietnam: Office of Ministry of Agriculture and Rural Development.

Statistics Office. (2017). Local area and productivity of rice in Phu Yen (Statistical Yearbook 2016). Phu Yen, Vietnam: Statistical Publishing House.

Zhang, Q. (2007). Strategies for developping green super rice. Proceedings of the National Academy of Sciences 104(42), 16402-16409. 